\title{
A FORMAÇÃO DE PROFESSORES DE EDUCAÇÃO FÍSICA EM IMAGENS: ACERVOS FOTOGRÁFICOS EM EXPOSIÇÃO
}

\author{
Meily Assbú Linhales \\ Cemef/UFMG \\ meily_linhales@yahoo.com.br \\ Verona Campos Segantini \\ Cemef/UFMG \\ veronasegantini@yahoo.com.br \\ Inés Scarlato García \\ CEMEF/ISEF/UdelaR \\ inescarlato@gmail.com \\ Paola Dogliotti \\ CEMEF/ISEF/UdelaR \\ paoladogliottimoro@gmail.com
}

\begin{abstract}
RESUMO
O presente texto tem como proposição apresentar experiências de organização de acervos históricos relativos à Educação Física em instituições de salvaguarda no Uruguai e no Brasil. Mais especificamente, pretende-se discutir processos de investigação a partir de acervos fotográficos que revelam aspectos das práticas de formação de professores de educação física nos dois países. Decorrentes desse processo de aproximação e diálogo relata-se o processo curatorial e de concepção de uma exposição fotográfica que buscou explorar tempos, espaços e as práticas selecionadas presentes na formação de futuros professores das escolas e das praças de jogos e esportes.
\end{abstract}

Palavras-chave: História da Educação Física. Formação de professores. Acervos fotográficos. Exposições.

\section{THE TRAINING OF PHYSICAL EDUCATION TEACHERS IN IMAGES: EXHIBITION OF PHOTOGRAPHIC COLLECTIONS}

\begin{abstract}
The present text proposes to present experiences of organization of historical collections related to Physical Education in safeguard institutions in Uruguay and Brazil. More specifically, it is intended to discuss research processes based on photographic collections that reveal aspects of the training practices of physical education teachers in both countries. As a result of this process of approximation and dialogue, the curatorial process and the conception of a photographic exhibition that seeks to explore the times, spaces and the selected practices present in the formation of future teachers of the schools and of the squares of games and sports.
\end{abstract}

Keywords: History of Physical Education. Teacher training. Photographic collections. Exhibitions. 


\title{
LA FORMACIÓN DE PROFESORES DE EDUCACIÓN FÍSICA EN IMÁGENES: ACERVOS FOTOGRÁFICOS EN EXPOSICIÓN
}

\author{
RESUMEN
}

El presente texto tiene como propósito presentar experiencias de organización de acervos históricos relativos a la Educación Física en instituciones de salvaguarda de Uruguay y Brasil. Más específicamente, se pretende discutir procesos de investigación a partir de acervos fotográficos que revelan aspectos de las prácticas de formación de profesores de educación física en los dos países. A partir de ese proceso de aproximación y diálogo se relata el proceso curatorial y de concepción de una exposición fotográfica que buscó explorar tiempos, espacios de las prácticas selecionadas presentes en la formación de los futuros profesores de las escuelas y las plazas de juegos y deportes.

Palabras clave: Historia de la Educación Física. Formación de profesores. Acervos fotográficos. Exposiciones.

\section{L'ÉDUCATION DES ENSEIGNANTS D'ÉDUCATION PHYSIQUE DANS LES IMAGES: COLLECTIONS PHOTOGRAPHIQUES EXPOSÉES}

\section{RÉSUMÉ}

Le présent texte propose de présenter des expériences d'organisation de collections historiques liées à l'éducation physique dans des institutions de sauvegarde en Uruguay et au Brésil. Plus précisément, il est prévu de discuter des processus de recherche basés sur des collections photographiques qui révèlent des aspects des pratiques de formation des enseignants d'éducation physique dans les deux pays. A la suite de ce processus d'approximation et de dialogue, le processus curatorial et la conception d'une exposition photographique qui cherche à explorer les temps, les espaces et les pratiques sélectionnées présentes dans la formation des futurs enseignants des écoles et des places de jeux et les sports.

Mots-Clés: Histoire de l'éducation physique. Formation des enseignants. Collections photographiques. Des expositions.

“Que horas são... lá, do outro lado?

Não será também - e, talvez, antes de mais nada - uma questão pessoal, uma dessas dúvidas íntimas sem a qual deixaríamos de ter gosto para revolver tantos arquivos e tanta poeira? [...] É possível pertencer a vários mundos e a vários tempos, sem tentar reduzi-los ou uniformizálos: não será essa a única maneira de tornar familiar a globalidade que nos cerca e nos invade?" (GRUZINSKI, 2012).

\section{INTRODUÇÃOO}

Por ocasião do XIII Congreso Iberoamericano Historia de la Educación Latinoamericana, realizado na cidade de Montevidéu, entre 28 de fevereiro e 03 de março de 2018, foi inaugurada a mostra fotográfica intitulada "Fragmentos da formação de professores de Educação Física em imagens - Uruguai e Brasil (1920-1970)”. Tal ação constituiu-se como 
desdobramento de uma parceria institucional que, desde 2016, vem sendo estabelecida entre equipes de trabalho responsáveis pela organização de acervos históricos relativos à Educação Física nos dois países. Do lado brasileiro, o grupo de trabalho vinculado ao Centro de Memória da Educação Física, do Esporte e do Lazer (Cemef), na Universidade Federal de Minas Gerais, em Belo Horizonte, criado em 2001 e em plena atividade na pesquisa história e nos processos de organização documental (LINHALES; NASCIMENTO, 2013), abordando especialmente o campo pedagógico da Educação Física e a formação de seus professores. Do lado uruguaio, também um centro de memória, cuja inauguração no Instituto Superior de Educación Física (ISEF), vinculado à Universidad de la República (UdelaR) aconteceu concomitantemente à abertura da referida mostra fotográfica. O Cemef/UFMG esteve presente nesse momento singular para o CEMEF/ISEF, reafirmando os vínculos de trabalho.

Entre as duas instituições, Cemef/UFMG e CEMEF/ISEF/UdelaR, os diálogos e parcerias se consolidam gradativamente, impulsionados pela constatação de que, ao longo do século XX, as experiências de formação docente e de afirmação da Educação Física como prática social e pedagógica realizadas nos dois países estiveram, em muitos momentos, conectadas. Alguns estudos históricos confirmam experiências de intercâmbio e produção mútua de referências em diferentes momentos dessa história (LINHALES, 2009; SILVA, 2017).

Dando continuidade às ações em parceria, o planejamento e a realização de uma mostra fotográfica demandou identificar pontos de conexão entre a formação de professores realizada na cidade de Montevidéu, no Uruguai, e aquela realizada na cidade de Belo Horizonte, no Brasil. Entre os variados tipos e suportes documentais, constatou-se que as fotografias permitem identificar, com riqueza de detalhes, os tempos e espaços utilizados nessas experiências de formação, as práticas selecionadas e os modos como os docentes transmitiam os saberes considerados relevantes aos futuros professores das escolas e das praças de jogos e esportes. Optou-se então por uma mostra fotográfica, como maneira de privilegiar as imagens tomadas como registros de um cotidiano da/na formação docente.

No Uruguai, o Curso para la Preparación de Profesores de Educación Física principiou suas atividades em 1939, passando a ser denominado Instituto Superior de Educación Física no ano de 1952. Neste mesmo ano, foram iniciadas as primeiras atividades de formação superior em Educação Física na cidade de Belo Horizonte. Entre os argumentos utilizados para a criação da primeira Escola de Educação Física na capital mineira, a experiência uruguaia foi apresentada como uma referência modelar. O documento intitulado "Necessidades de Criação da Escola de Educação Física e Desportos de Minas Gerais”, publicado em 1945, cujos autores 
tornaram-se professores da Escola fundada em 1952, fez circular diferentes representações de Educação Física, agregando destaque à formação em Curso no Uruguai, citado como "um dos países da América Latina em que a Educação Física se encontra mais adiantada” (NECESSIDADE...,1947, p. 08).

Em perspectiva histórica, pretendíamos que as fotografias selecionadas fossem capazes de entrelaçar esses diferentes percursos institucionais. Na pesquisa inicial que orientou as escolhas para a exposição partimos do pressuposto de que livros, manuais, práticas, professores e alunos, cada um a seu modo, fizeram circular saberes e prescrições entre os dois países. Buscou-se então identificar, nas 36 fotografias selecionadas, os fragmentos estéticos, as modelagens pedagógicas e as maneiras de fazer com o corpo nas escolas, nas praças, nas cidades. Tais atividades constituem, também, o fazer dos Centros de Memória.

\section{NARRATIVAS EXPOSITIVAS COMO PROCESSOS DE INVESTIGAÇÃO}

Embora os Centros de Memória possuam, muitas vezes, características híbridas em relação às suas vocações (arquivos, museus e bibliotecas), podemos definir que diferentes estratégias de extroversão e acesso aos acervos devem ser mobilizadas. Nessa perspectiva, são inúmeras as possibilidades de pesquisas que se apresentam, bem como uma multiplicidade de temas e questões que são conformadas nos processos de concepções de exposições. No presente texto iremos privilegiar uma perspectiva museológica dos Centros de Memória, dando relevo, sobretudo, às exposições como linguagem privilegiada para a extroversão de acervos e visibilidade dos processos de salvaguarda e de investigação que são operados nestes importantes espaços que se inseriram em diferentes universidades nas últimas décadas.

Se partirmos de uma definição consolidada em relação às funções dos museus, quais sejam: preservação, pesquisa e comunicação - incorremos no risco de tratar tais aspectos de maneira fragmentária ou, por vezes, de maneira hierarquizada. As exposições são reconhecidamente a linguagem caracterizante dos museus, contempladas, portanto, como uma importante ação de comunicação museológica. Embora se reconheça conceitualmente as exposições como "parte integrante do processo de pesquisa, mas, também como elemento de um sistema de comunicação mais geral, compreendendo, por exemplo, as publicações científicas" (DESVALLÉES; MAIRESSE, 2013, p. 35), contraditoriamente, essas são vistas como resultado "fim". 
Tomamos como ponto de partida as experiências expositivas que têm sido desenvolvidas no âmbito da UFMG e, mais especificamente no Cemef, desde 2011. ${ }^{1}$ Tais experiências demonstram como essas funções, embora ainda não ocupando de maneira equânime nas dinâmicas institucionais, estão imbricadas e se alimentam continuamente. Embora, muitas vezes, as exposições ou os processos de comunicação museológica apareçam como resultados de um longo processo de investigação, podemos ressalvar que estas também podem ser mobilizadas como um momento de reflexão e interpretação sobre o acervo. Queremos, portanto, sublinhar que um exercício curatorial ou a concepção de uma exposição conforma-se também como processo de investigação. Alimenta, com isso, outros caminhos de pesquisa e novas possibilidades de conexão.

No âmbito das universidades, as exposições são fundamentais, muitas vezes, para a apresentação dos acervos que possuem um potencial de musealização e que ainda não foram reconhecidos e/ou legitimados como patrimônio universitário. Em alguns casos, acervos em risco ao se inserirem nessa lógica expositiva passam a fomentar o debate sobre a salvaguarda. Também, incorporadas aos momentos de celebração, as exposições tornam-se convite a revistar os acervos, encontrar novas conexões, construir narrativas a partir de uma coleção materializada em diferentes tipologias documentais. Muitas vezes, são construídas a partir de fios ou rastros biográficos, a partir de acervos/arquivos pessoais de professores doados ou adquiridos pelas universidades. Potencializam, com isso, outros processos de incorporação, garantindo a diversidade de registros das práticas de formação e produção do conhecimento realizadas nas universidades ao longo do tempo (SEGANTINI; JULIÃO, 2017). Todas essas motivações e circunstâncias, presentes nas experiências expositivas desenvolvidas pelo Cemef/UFMG desde a sua criação, são agora compartilhadas com o CEMEF/ISEF em uma nova e relevante etapa no percurso.

Nesses processos de visualização dos acervos torna-se fundamental um exercício curatorial que parta de objetivos ou temáticas que são, muitas vezes, delineados nos processos de investigação e/ou preservação e de descrição do acervo. Reconhecer, portanto, o repertório dos acervos incluindo outros conjuntos documentais que não se limitam à própria instituição é premissa para proposições de narrativas expositivas que ofereçam interpretações inaugurais. Este foi o caso da mostra fotográfica “A formação de professores de Educação Física em imagens - Uruguai e Brasil (1920-1970)”. Reconhecendo pontos de conexão entre dois acervos,

\footnotetext{
${ }^{1}$ No âmbito do Cemef/UFMG já foram realizadas 05 exposições temáticas. Todas elas tomaram como referência e ponto de partida o acervo do Centro bem com os estudos históricos realizados por seus investigadores (LINHALES et al, 2011; 2017).
} 
o trabalho curatorial implicou colocar em contraste, comparar, selecionar, interpretar fotografias que revelassem aspectos da formação de professores nas duas instituições. Desse exercício foi possível propor uma narrativa expositiva que partiu da interpretação das imagens e definição de temáticas, que serão apresentadas adiante.

Outro aspecto fundamental das exposições é reconhecer que para além do acervo selecionado há que se construir um diálogo com o espaço que abrigará essa narrativa. Na sede o ISEF/Udelar, em Parque Batlle, uma sala de aula foi escolhida - a sala de espelhos respeitando sua materialidade, marcas do uso e do tempo. Nesse aspecto, não se busca "anular" a superfície expositiva, mas inseri-la em uma ambiência que expresse e faça parte da narrativa curatorial. Também é fundamental pensar no diálogo com outras tipologias de acervo como, por exemplo, mobiliários, equipamento e instrumentos. Muitas vezes estão representados nas imagens e registros das instituições, mas foram, ao longo do tempo, perdendo sua função de uso e relegados aos depósitos presentes em quase todas as universidades. As exposições chamam atenção para esses objetos que fizeram parte das dinâmicas dessas instituições. Assim sendo, alguns aparelhos como barras paralelas, traves de equilíbrio, cavalos, postes e redes de voleibol, entre outros equipamentos, foram inseridos, dando destaque à sua materialidade e recriando seus usos, transformados em suportes expositivos.

Figura 1: Aparelho ginástico utilizado como suporte expográfico na Mostra Fotográfica "Fragmentos da formação de professores de Educação Física em imagens - Uruguai e Brasil (1920-1970)".

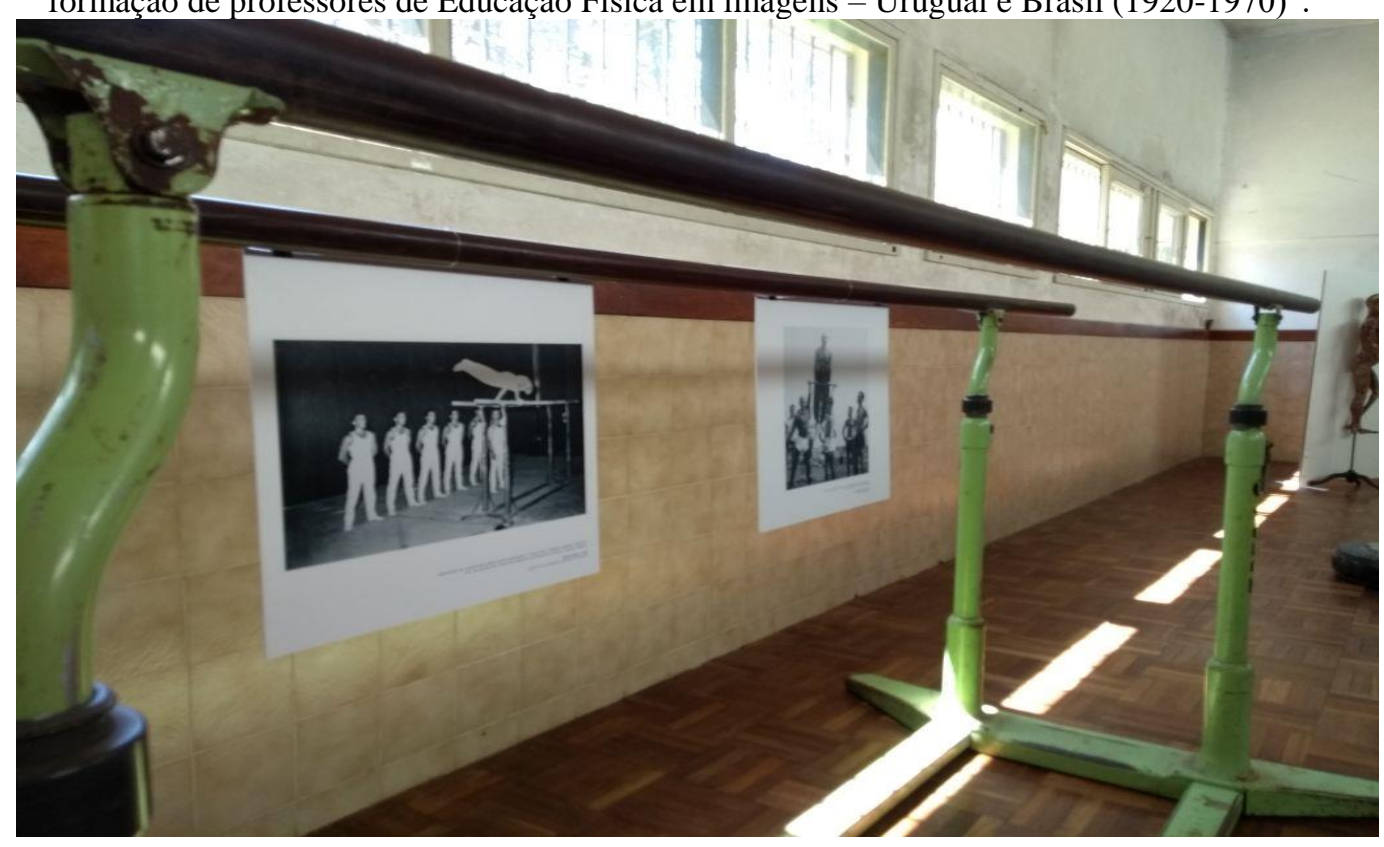

Fonte: Montevidéu, 2018. 
Figura 2: Equipamentos ginásticos e esportivos utilizados como suporte expográfico na Mostra Fotográfica "Fragmentos da formação de professores de Educação Física em imagens - Uruguai e Brasil (1920-

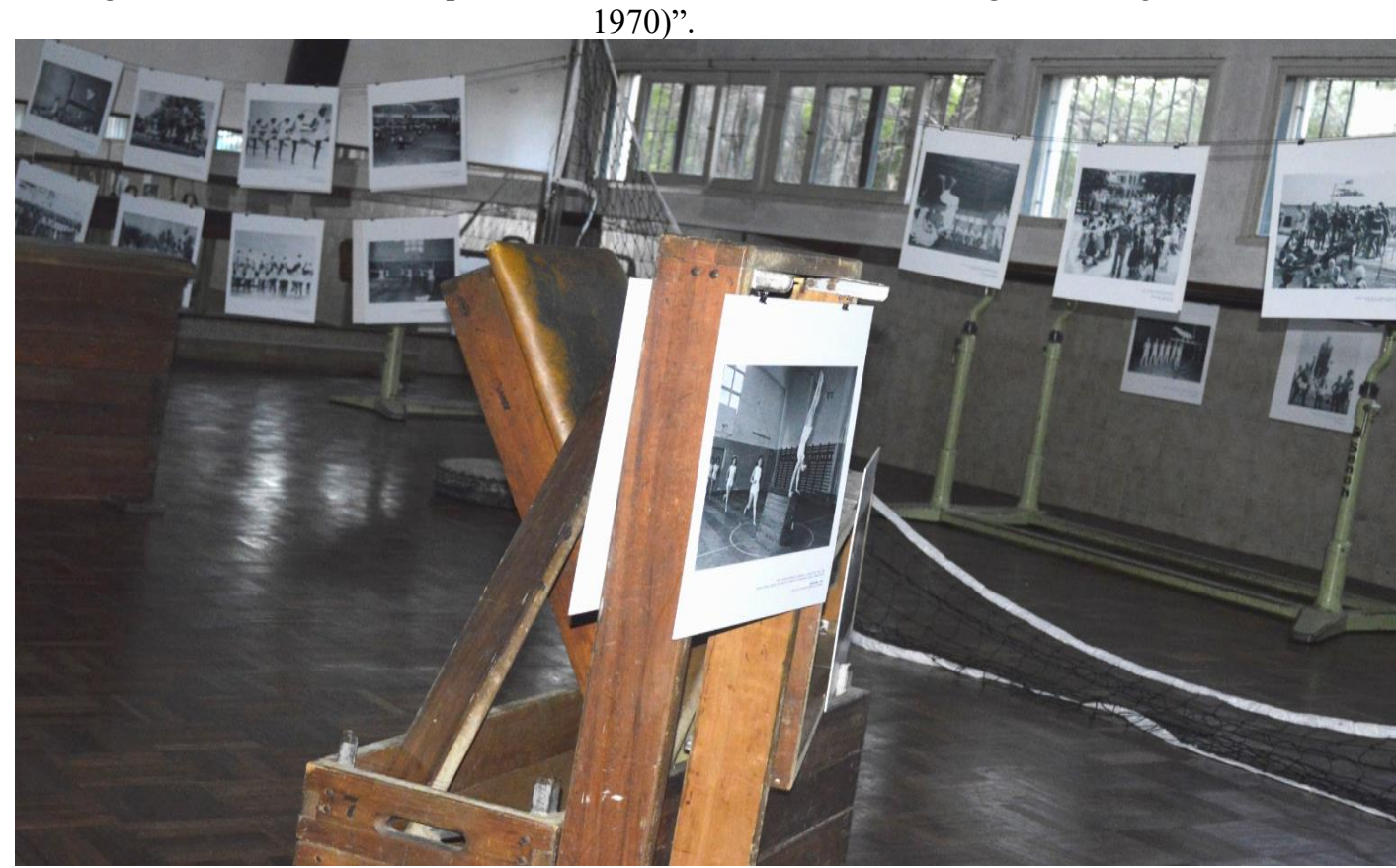

Fonte: Montevidéu, 2018.

Todos esses elementos foram precedidos dos exercícios de seleção de fotografias, realizados nas duas instituições. As mesmas deveriam retratar aspectos diversos das experiências de formação de professores de Educação Física.

\section{A SELEÇÃO DE IMAGENS NO ISEF/UDELAR}

É muito recente a descoberta e a valorização de imagens que retratam fragmentos da história da educação física uruguaia. Em 2014, o ISEF teve contato com um grande número de álbuns de fotografias (noventa e quatro), de propriedade do Ministerio de Turismo y Deporte $(M T y D)$, hoje Secretaría Nacional de Deportes (SND). Tais álbuns reúnem aproximadamente 10.000 fotografias provenientes da Comisión Nacional de Educación Física (CNEF) do Uruguai, acumuladas desde o ano de 1915 até a década de 1960 (SCARLATO, 2015) e foram retirados de um subsolo do edifício do $M T y D$, alguns já com o estado de conservação comprometido devido à umidade do local. Felizmente, em 2015, foi celebrado um convênio entre a SND e o Centro de Fotografía de Montevideo (Cdf) com o propósito de conservar, acondicionar e organizar o acervo fotográfico.

As fotografias retratam diversos cenários, entre os quais destacam-se competições e encontros esportivos de futebol, basquetebol, boxe, ciclismo, remo, natação, entre outros. Instalações da CNEF como praças de desportos, piscinas, aparatos ginásticos nas praias, que 
mostram atividades de crianças, jovens, homens e mulheres com e sem direção técnica, entre outras diversas cenas relativas à cultura física do país. Além disso, entre essas temáticas destacam-se algumas curiosidades, como alguns álbuns organizados especificamente para difundir as práticas de cultura física do país no exterior, utilizados em viagens de algum membro da CNEF. Também um álbum que reúne fotografias de uma praça de desportos construída na cidade de Bagé (no Rio Grande do Sul), com a direção técnica da CNEF. Estes elementos mostram a potencialidade desse arquivo, que será inaugurado como uma parceria entre a SND e o Cdf, para a pesquisa em história da educação física e das práticas corporais no Uruguai e para além das fronteiras do país.

A seleção realizada no âmbito da mostra fotográfica partiu desse acervo fotográfico do $\mathrm{CDF}$, que está sob a guarda do Cdf, e ambas as instituições apoiaram a realização, colocando à disposição as equipes de trabalho que colaboraram com a digitalização do material. Foram selecionadas 18 fotografias que apresentam distintos momentos de formação de professores, incluindo algumas que antecedem a criação do Curso para la Preparación de Profesores de Educación Física, em 1939, e do próprio ISEF, em 1952 (DOGLIOTTI, 2015). A participação do Professor Arnaldo "Cheche" Gomensoro" ${ }^{2}$ neste processo foi imprescindível, como conhecedor, apaixonado e engajado na reconstrução da história da educação física uruguaia.

\section{A SELEÇÃO DE IMAGENS NO CEMEF/UFMG}

Conforme argumentam Moreno e Segantini (2013), o trabalho de organização de parte do acervo iconográfico no Cemef/UFMG foi iniciado em 2007 e, por meio de sucessivos projetos de extensão universitária, foram envidados esforço de identificação, guarda e disponibilização de um conjunto composto por 2.462 fotografias. São imagens que, em sua grande maioria, retratam momentos solenes e práticas diversas, experimentadas por alunos e

\footnotetext{
${ }^{2}$ Arnaldo é professor de Educação Física uruguaio. Começou seus estudos no ISEF, no ano 1964, e finalizou em 1966. Atuou como professor na formação de técnicos, professores e licenciados em educação física no ISEF, na Asociación Cristiana de Jóvenes (ACJ), na Universidad de la Empresa e na Universidad CLAEH de Montevidéu. É editor da revista NEXO Sport e integrante do Grupo de Estudios del Fútbol Uruguayo da Facultad de Humanidades y Ciencias de la Educación de la Universidad de la República. É assessor da Secretaria Nacional del Deporte e Coordenador da Unidade Temática "Deporte" na Comisión Nacional de Programa del Frente Amplio. Autor do livro "Historia del Deporte, la Educación Física y la Recreación del Uruguay. Crónicas y Relatos", publicado pela Ed. IUACJ Montevideo 2015. Autor de artigos, coautor de livros e colaborador de várias publicações sobre a história da Educação Física e do esporte do Uruguai. É membro do Comité Académico do Centro de Memoria de Educación Física do ISEF-Udelar. Além de tudo, é um incansável e apaixonado narrador de anedotas e grande colaborador, reconhecido por sua generosidade em compartilhar seus conhecimentos e percursos na história da educação física uruguaia.
} 
professoras da Escola de Educação Física ao longo de sua história. Na fase atual do tratamento arquivístico, as fotografias estão organizadas em séries temáticas.

A partir das fotografias selecionadas pela equipe de trabalho do ISEF/UdelaR, o conjunto documental do Cemef/UFMG foi revisitado por uma pequeno grupo de trabalho: os professores Diogo Puchta e Meily Linhales, a doutoranda Cássia Danielle Monteiro Dias Lima (que durante sua graduação havia sido bolsista no Centro e atuado junto a este acervo) e o atual bolsista de extensão, Felipe Carisio. O primeiro movimento foi o de buscar nas imagens mineiras os pontos de conexão com as fotografias selecionadas no Uruguai: diferentes práticas (danças, ginásticas, atividades aquáticas, etc.), locais de execução (aulas em ginásios, ao ar livre, na cidade, etc.) situações solenes, entre outras.

De uma seleção inicial de aproximadamente 30 fotografias, realizou-se uma segunda triagem, priorizando aquelas que permitiriam os exercícios de descrição para as legendas e/ou aquelas que melhor se ajustavam ao trabalho técnico de ampliação das imagens. Também foi priorizada uma fotografia que retrata a visita de um professor uruguaio a Minas Gerais na década de 1950 e outras com práticas de danças típicas dos pampas. As 18 imagens finalmente selecionadas dão a ver fragmentos da Educação Física e da formação de seus professores em Minas Gerais, entre as décadas de 1950 e 1970. Todas elas pertencem ao acervo de Centro e foram acumuladas pela instituição ao longo dos anos. Em geral, são raras as informação sobre a autoria das fotografias.

\section{O EXERCÍCIO CURATORIAL, INTERPRETAÇÕES E CONEXÕES}

Para a montagem da exposição, no ISEF/UdelaR, procedemos a um exercício de organização das 36 fotografias selecionadas, levando em consideração algumas conexões temáticas: tipos de práticas, imagens internas ou ao ar livre, fotografias com bandeiras das instituições e países, entre outras. Ao mesmo tempo, era necessário adequar a distribuição das mesmas à setorização estabelecida para a exposição em seu desenho inicial. Tal setorização incluía a disposição dos expositores no espaço, prevendo com isso, um percurso de visitação. Embora haja um processo de reflexão sobre o espaço que repercutem na elaboração de geração de alternativas, croquis e finalmente projetos que subsidiem as decisões técnicas e conceituais, muitas vezes, na experiência de montagem das exposições, é necessário rever e ajustar o projeto de acordo com as demandas e imprevistos que ocorrem. A combinação desses vários aspectos faz com que cada exposição seja única, pois o processo de tomada de decisões costuma subverte o desenho originalmente pensado. Ou seja, ela é "fabricada" também no instante de sua 
montagem, mediante as condições objetivas disponíveis, podendo inclusive, serem pensadas novas conexões entre os acervos/objetos e o espaço expositivo.

Figura 3: Muestra Fotográfica.

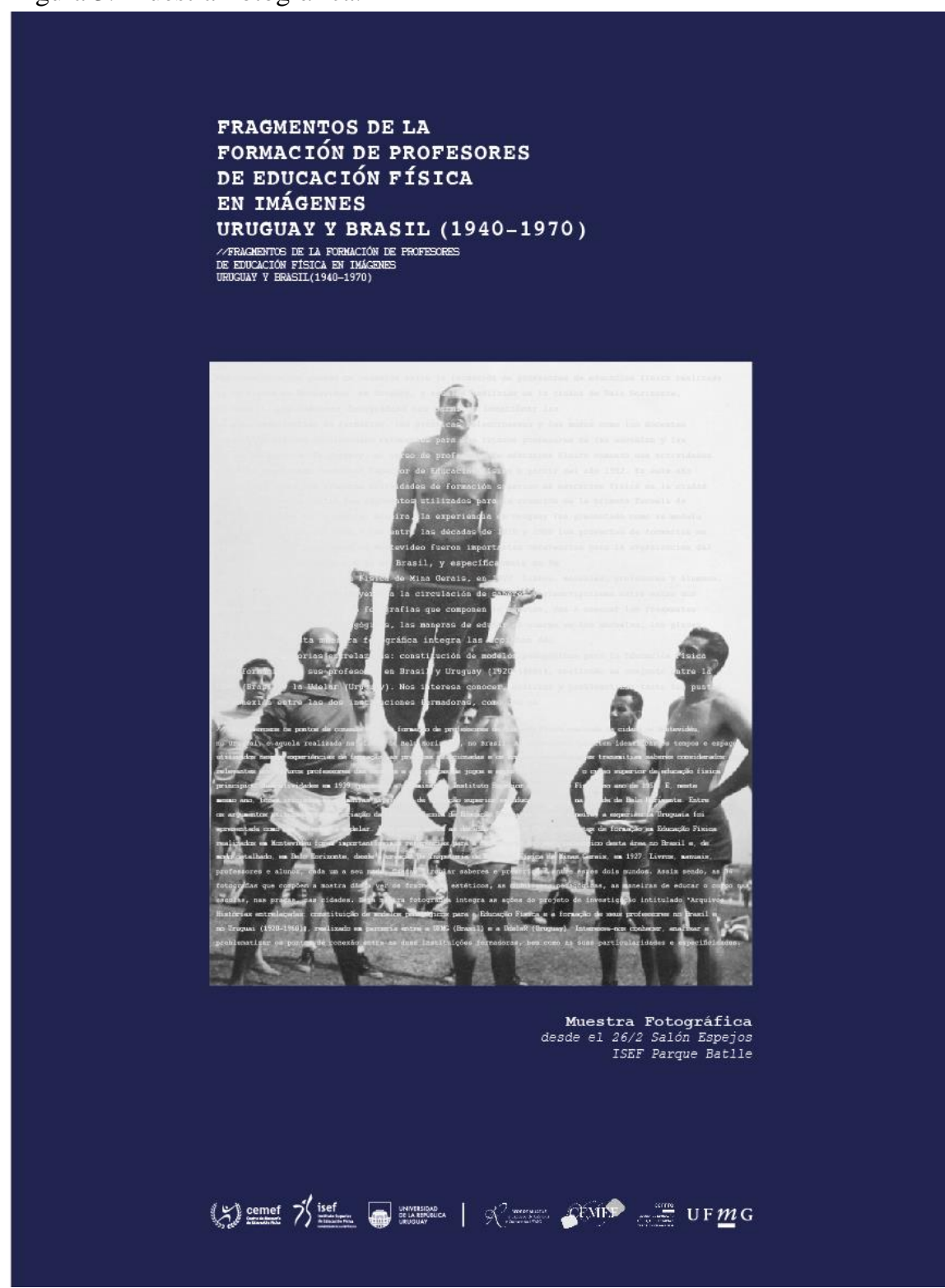

Fonte: Disponível em: <http://isef.edu.uy/noticias/muestra-fotografica/>.

Outro elemento importante a ser considerado é o minucioso trabalho de elaboração das legendas que acompanham as fotografias. Pareceu-nos imprescindível indicar a atividade em questão, os sujeitos que dela participavam, bem como o ano de sua realização e o local retratado. Todas as legendas deveriam obedecer uma mesma lógica de informação, sem que se transformassem em textos muito longos. Este é um exercício narrativo que demanda pesquisa sobre os detalhes revelados e algum conhecimento histórico acerca dos temas em questão. As 
pesquisas desenvolvidas subsidiam a elaboração dessas informações e também sugerem temáticas a serem melhor exploradas.

Assim construída, a tessitura desta exposição nos permitiu identificar imagens - de Montevidéu e de Belo Horizonte - que, embora distantes no espaço, pareciam “conversar" entre si. Os rituais da e na formação de professores de Educação Física, os estilos de aulas, as práticas corporais estabelecidas como conteúdo e experienciadas na preparação docente, as marcas de um tempo em comum ou as maneiras de ocupar as cidades foram alguns dos elos de conexão que a exposição pretendeu dar a ver, a ler, a sentir...

Passamos a apresentar algumas das imagens que compuseram a exposição, com suas respectivas legendas, em espanhol ou em português, conforme origem das fotografias:

Figura 4: Primeros estudiantes en la Inauguración del Curso para la Preparación de Profesores de Educación Física. Sede Comisión Nacional de Educación Física. Montevideo, 1939.

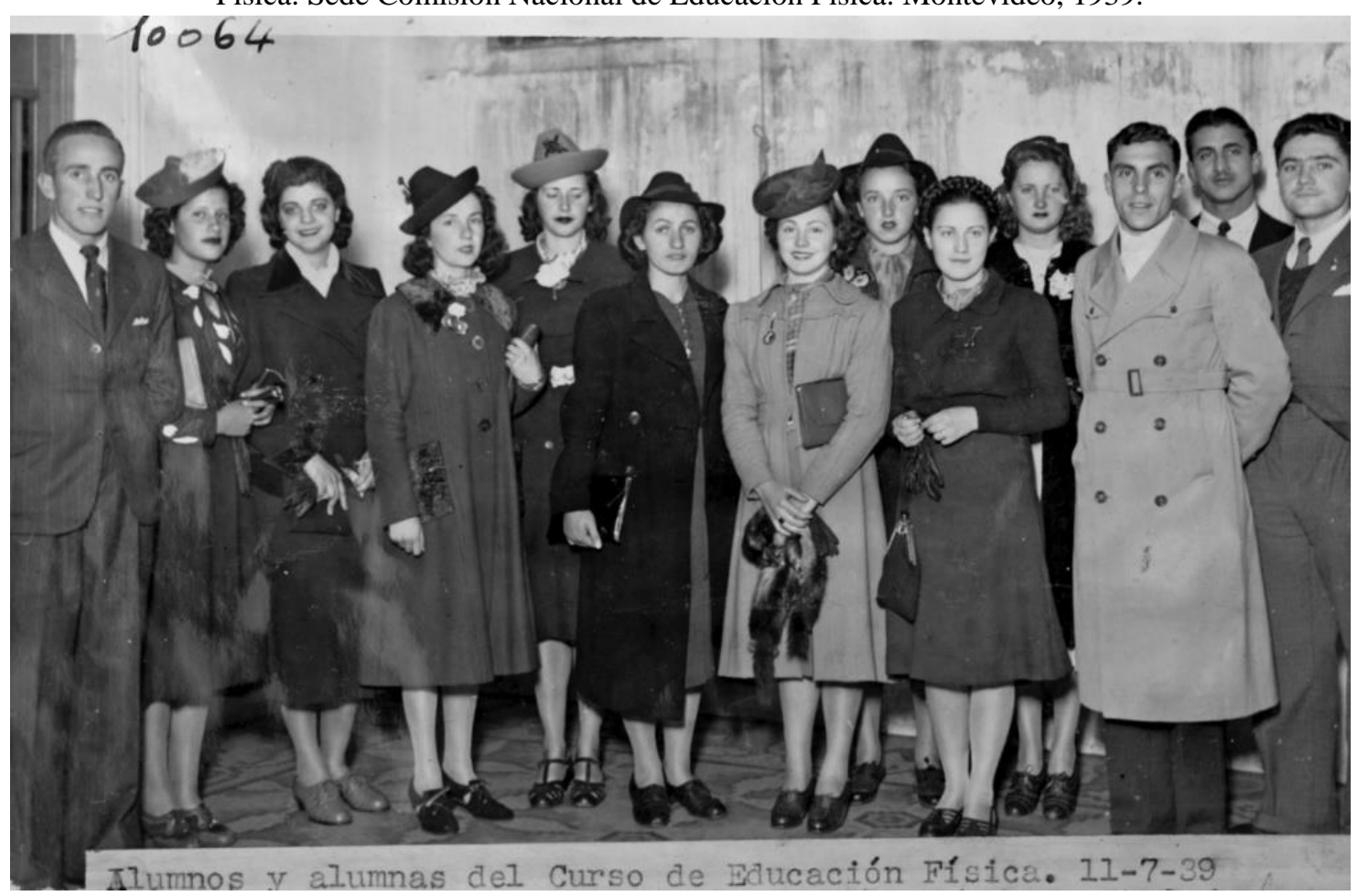

Fonte: Acervo de la Secretaría Nacional de Deporte. 
Figura 5: Alumnos "Gimnástica Educativa Masculina” a cargo Prof. Alberto Langlade. Pista Oficial Atletismo Parque Batlle. Montevideo, 1957.

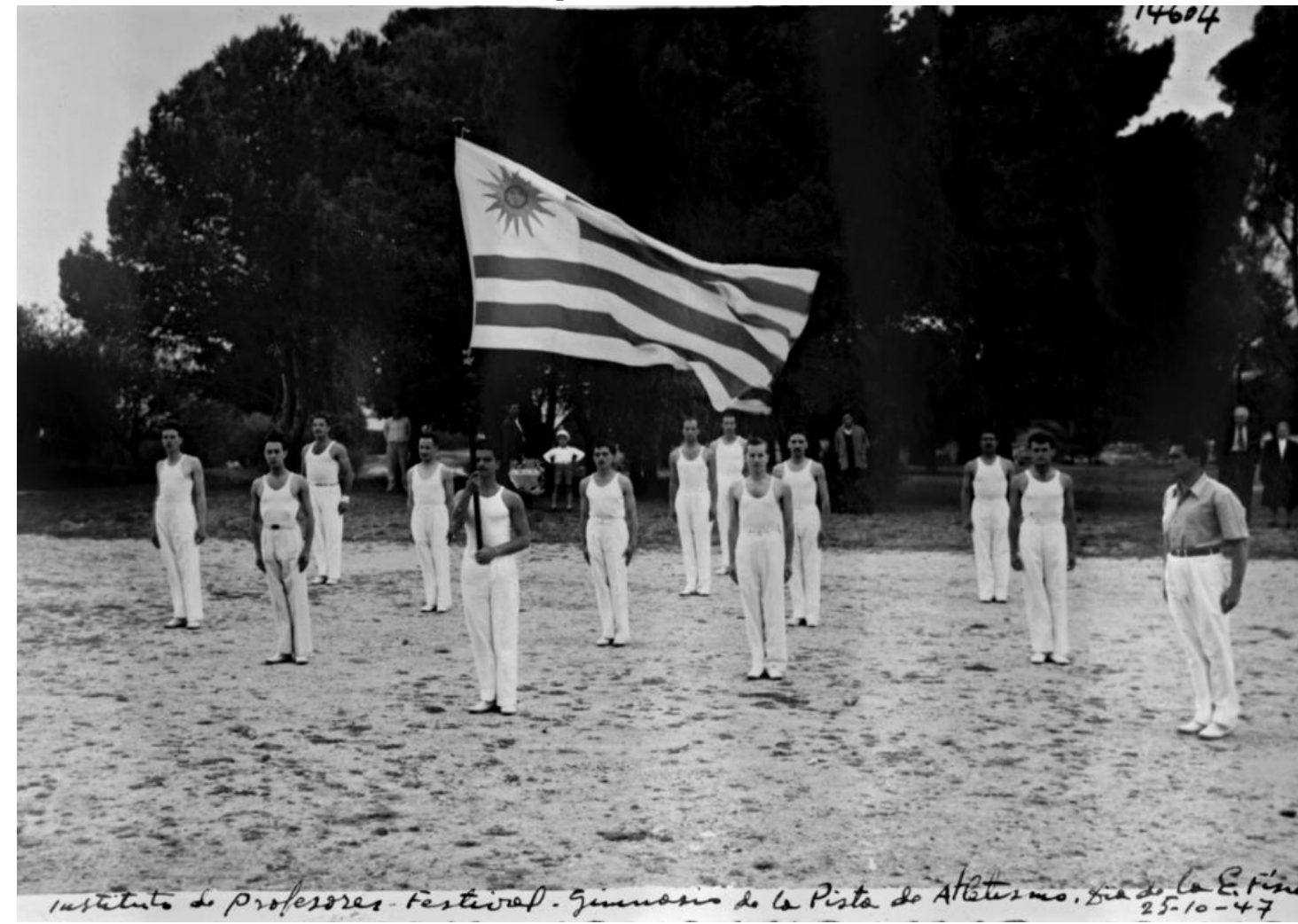

Fonte: Acervo de la Secretaría Nacional de Deporte.

Figura 6: Alumnos Curso Profesores ISEF. Exhibición danza folclórica. $8^{\text {a }}$ Conferencia de Unesco, Auditorio del Sodre. Montevideo, 1954.

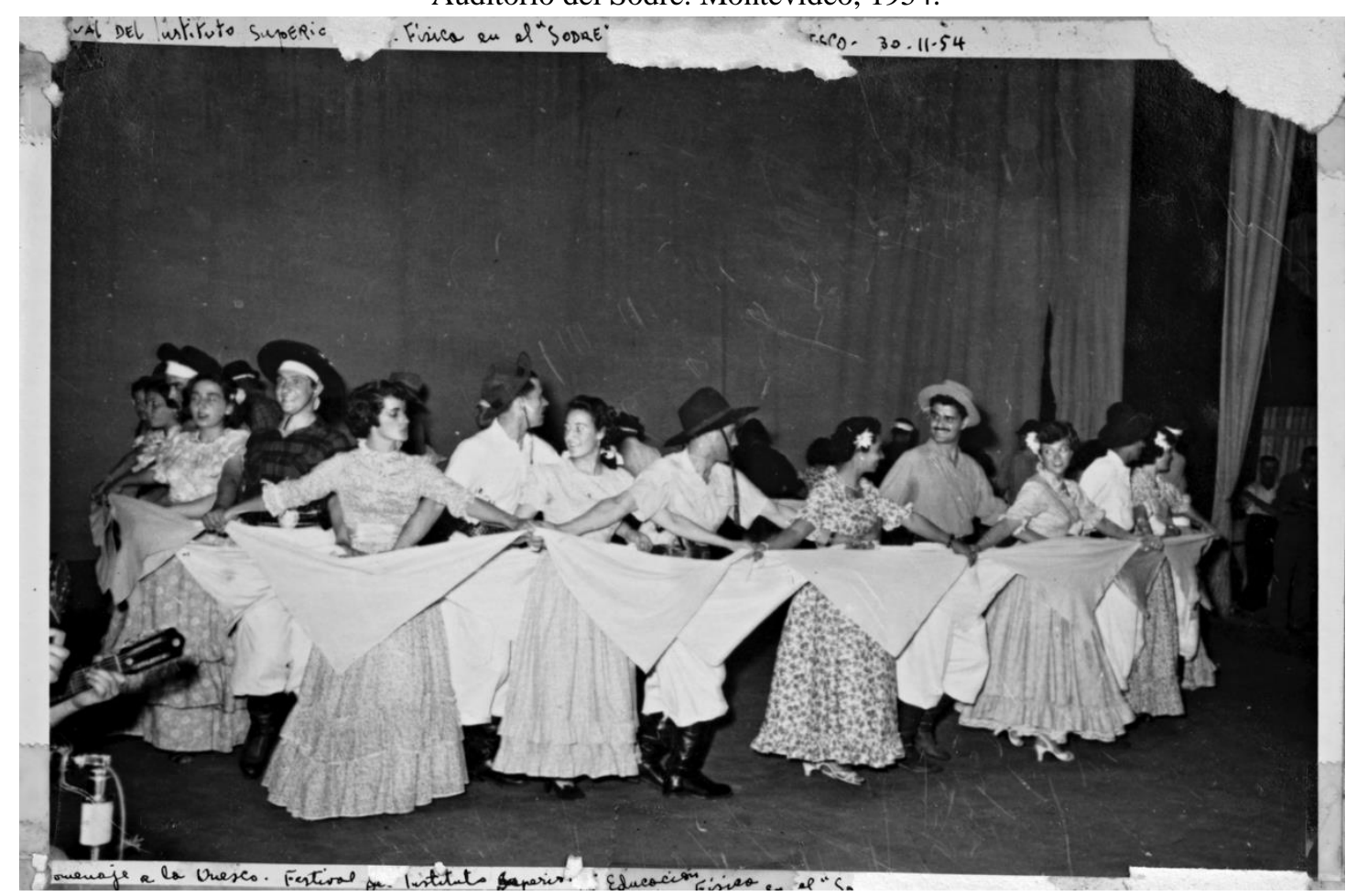

Fonte: Acervo de la Secretaría Nacional de Deporte. 
Figura 7: Clase teórica a cargo del Prof. Julio J. Rodríguez. Parque junto a Hotel Atlántida. Montevideo, 1924.

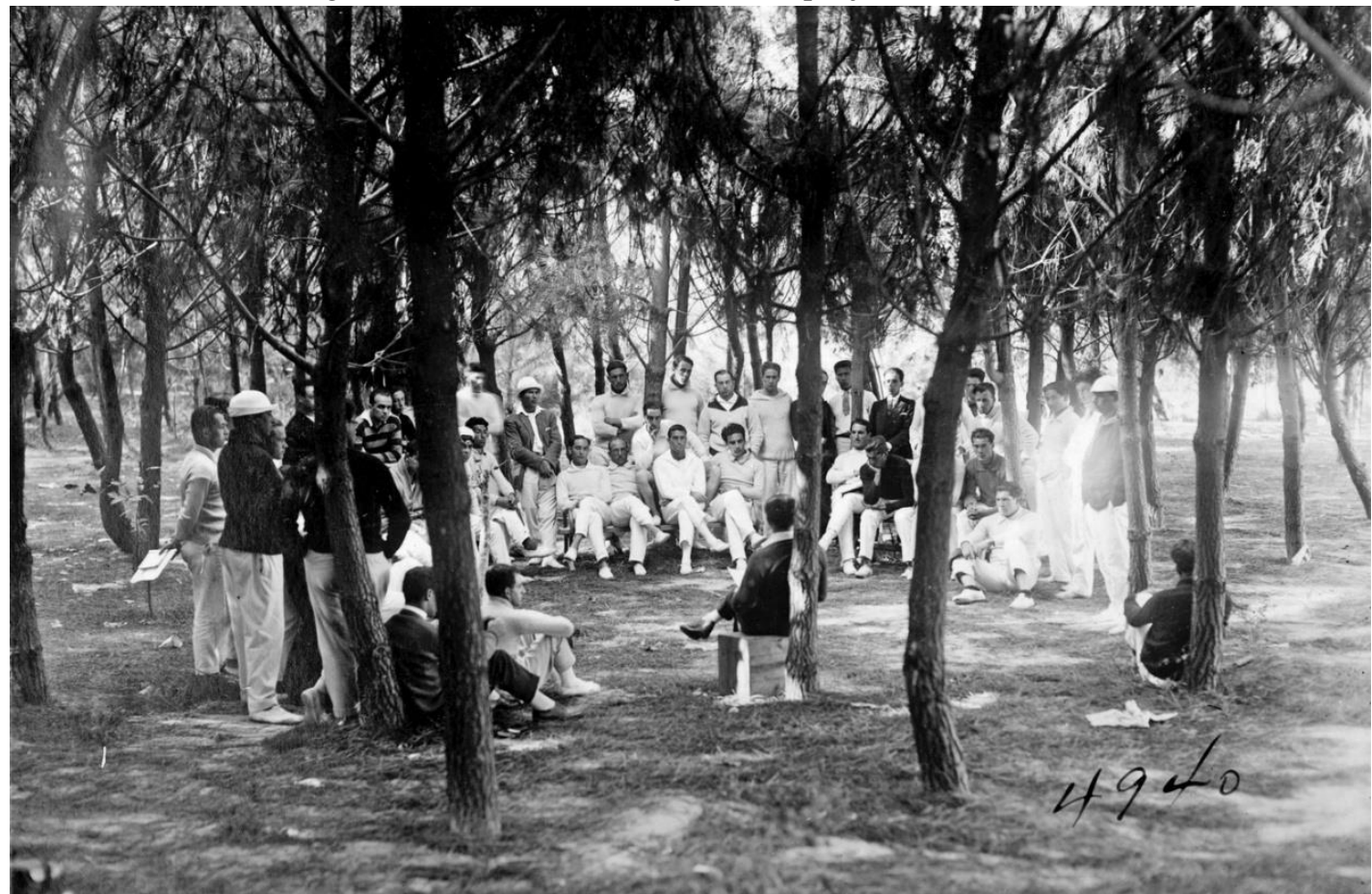

Fonte: Acervo de la Secretaría Nacional de Deporte.

Figura 8: Alunas da $1^{\mathrm{a}}$ turma do Curso de Educação Física Infantil, no dia da formatura. Belo Horizonte, 1952.

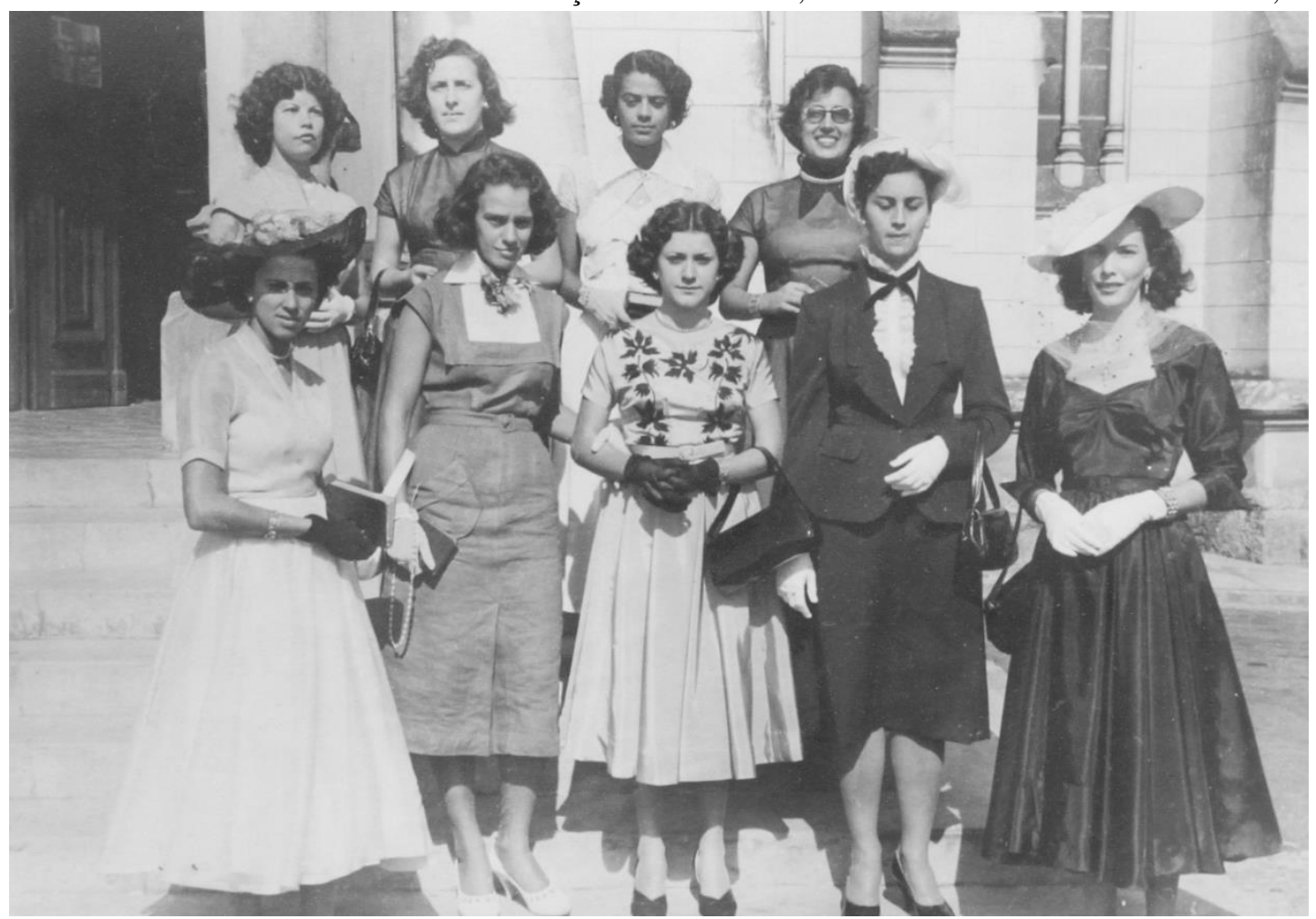

Fonte: Acervo do Cemef/UFMG. 
Figura 9: Grupo de Danças Folclóricas no gramado da Escola de Educação Física de Minas Gerais. Belo Horizonte, Década de 1960.

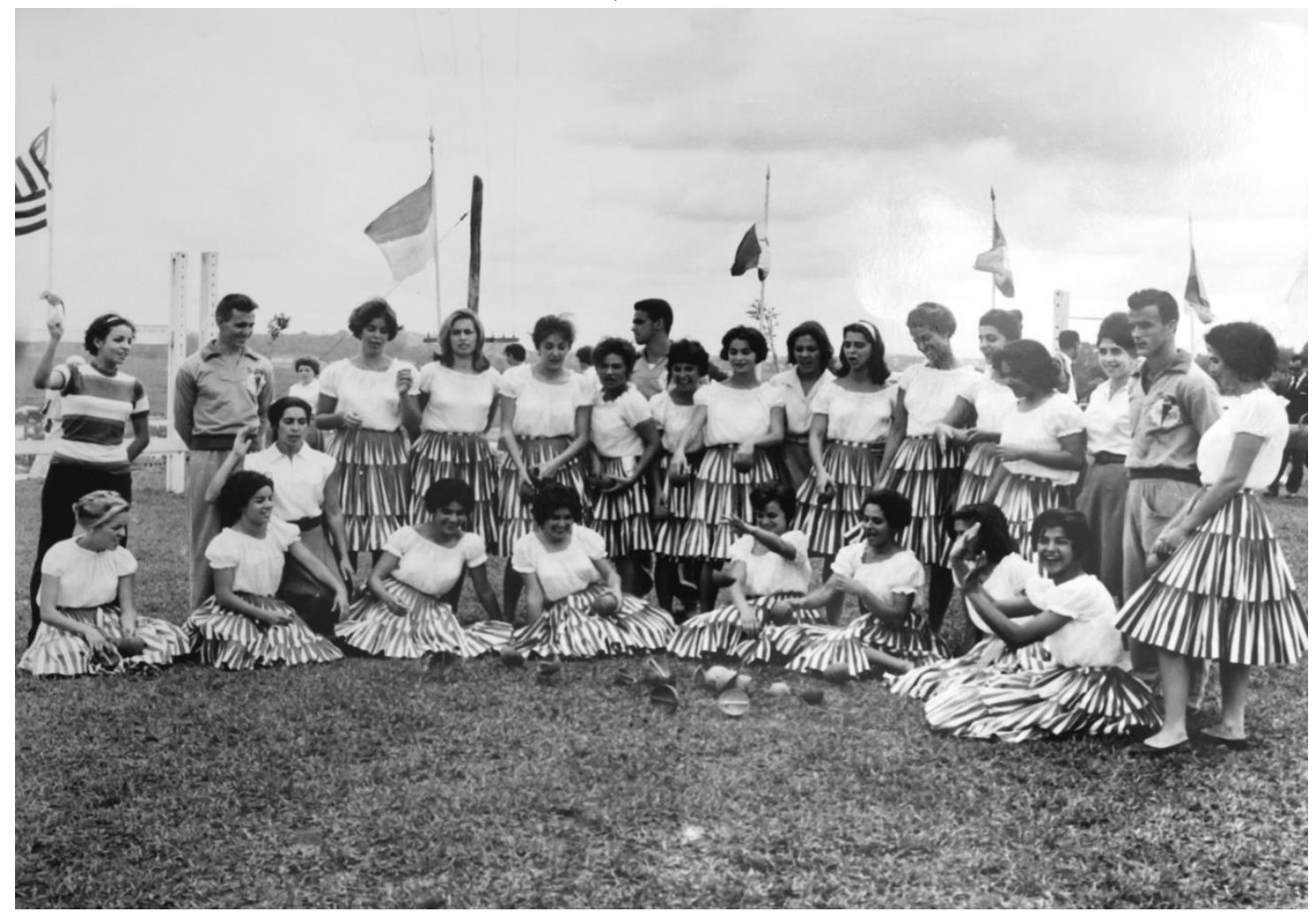

Fonte: Acervo do Cemef/UFMG.

Figura 10: Momento recreativo na piscina da Escola de Educação Física de Minas Gerais com o professor Odilon Ferraz Barbosa. Belo Horizonte, 1966.

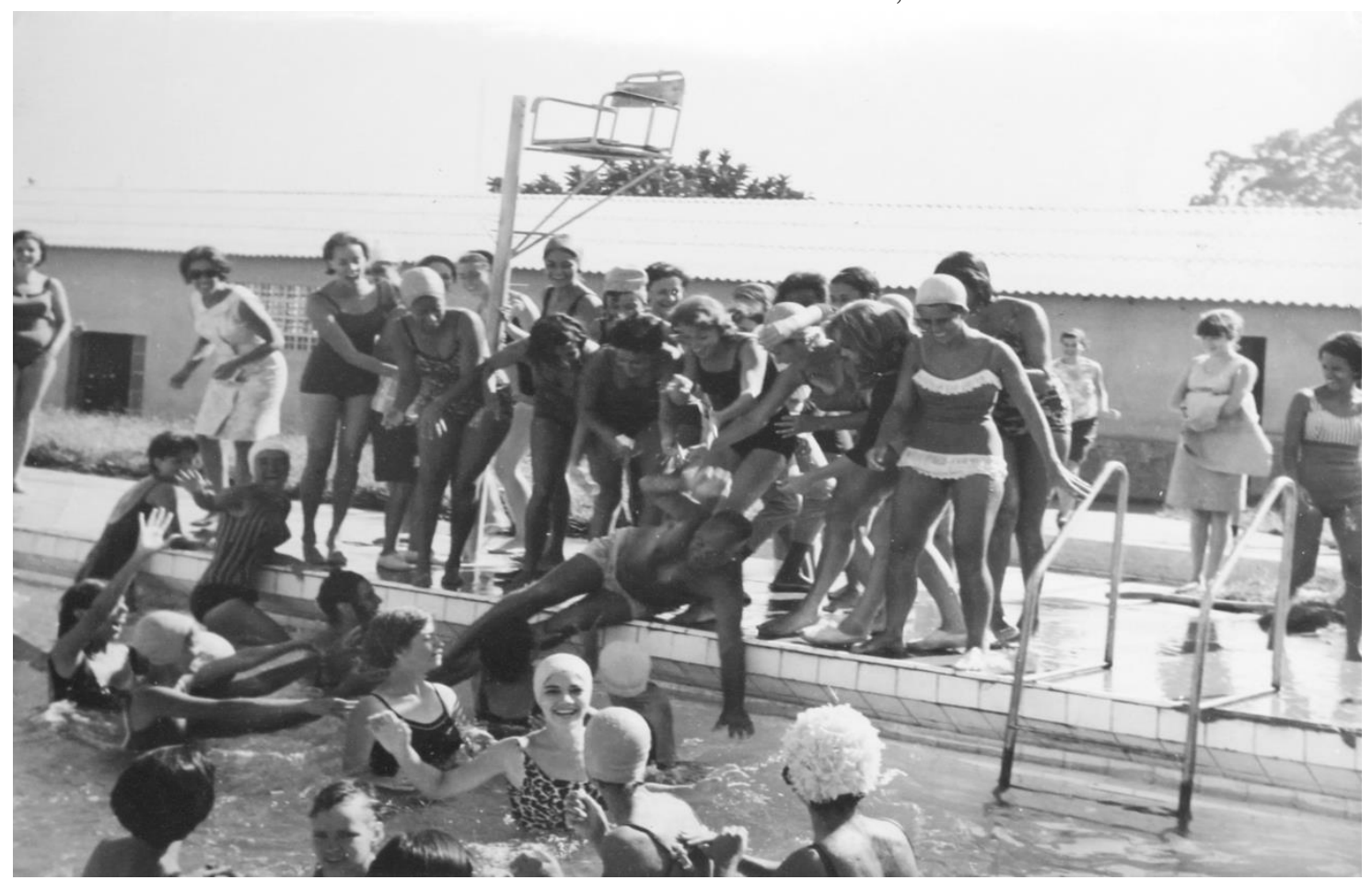

Fonte: Acervo do Cemef/UFMG. 
Figura 11: Rua de Recreio organizada por alunos da Escola de Educação Física de Minas Gerais. Pará de Minas, Década de 1950.

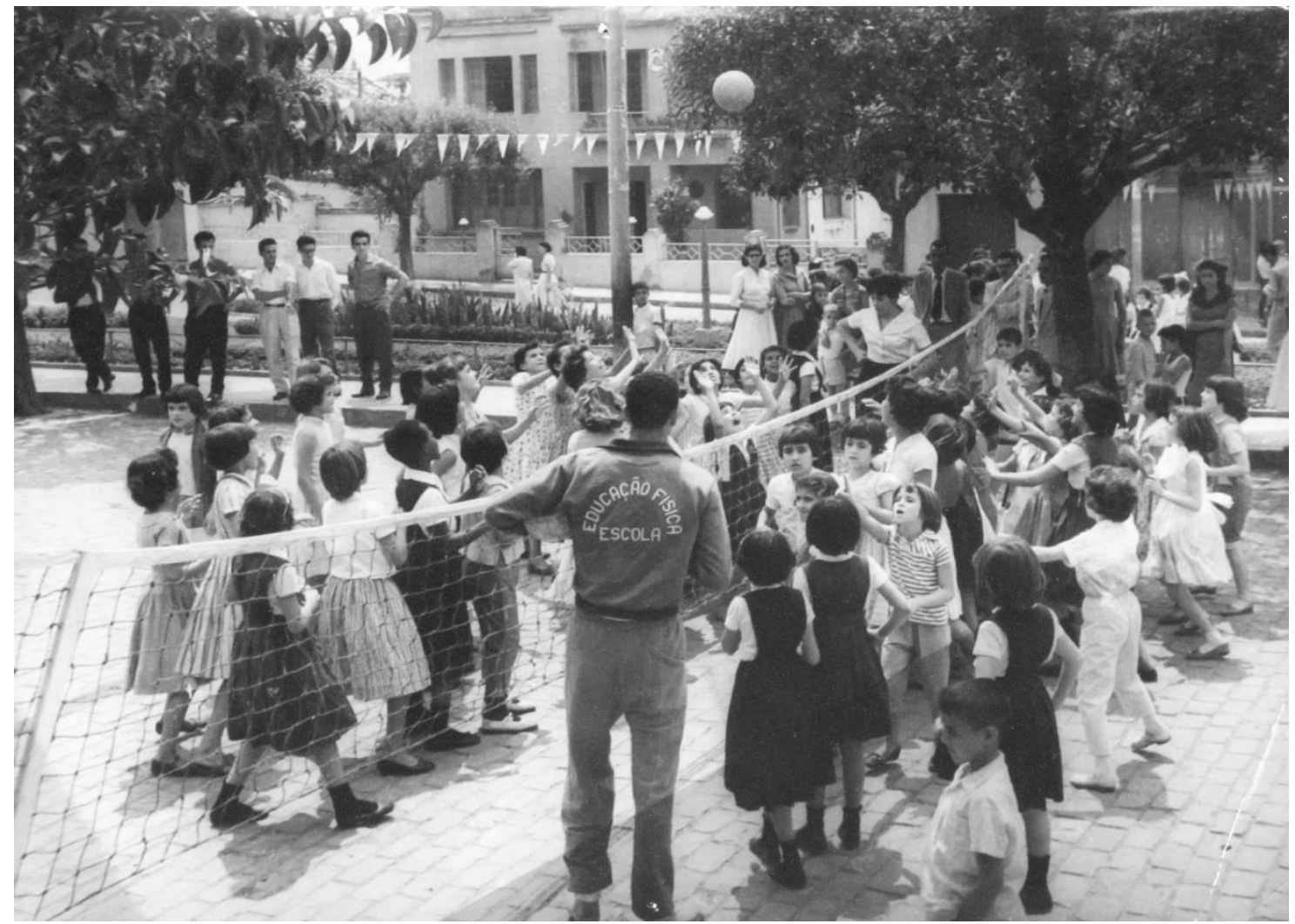

Fonte: Acervo do Cemef/UFMG.

\section{DESAFIOS, DESDOBRAMENTO E NOVOS DIÁLOGOS EM EXPERIÊNCIAS PARTILHADAS}

A mostra fotográfica intitulada "Fragmentos da formação de professores de Educação Física em imagens - Uruguai e Brasil (1920-1970)” receberá uma segunda montagem em setembro de 2018, na Escola de Educação Física, Fisioterapia e Terapia Ocupacional (EEFFTO) da UFMG, por ocasião da realização do X Seminário do Cemef, que terá como temática os "Diálogos transnacionais na História da Educação Física". Nesse novo tempo e lugar, as mesmas 36 fotografias e suas respectivas legendas serão, mais uma vez, submetidas a um diálogo com os aspectos materiais, os espaços, os suportes, os limites orçamentários e as novas expectativas. Ou seja, uma nova "fabricação", que implicará, outros processos de decisão, outras narrativas a serem construídas. Razão de ser e importância dos trabalhos de investigação que incluem a curadoria, que forja e constrói uma narrativa a partir de objetos, e a expografia, que dá materialidade a essa narrativa, possibilitando o diálogo entre a coleção, o espaço e o visitante. 
Neste texto, nosso principal objetivo consistiu em relatar os complexos processos de seleção, preparação e extroversão dos documentos históricos para uma narrativa expositiva sobre formação de professores de Educação Física. Tarefa desafiadora que, ao possibilitar a visibilidade aos processos de salvaguarda, próprios aos Centros de Memória, possibilitou também que, como pesquisadoras, pudéssemos saborear o privilégio de "pertencer a vários mundos e a vários tempos, sem tentar reduzi-los ou uniformizá-los", como destacado no texto de Serge Gruzinski trazido com epígrafe.

\section{Fontes}

\section{Em Belo Horizonte}

- Acervo do CEMEF/UFMG. Fundo Escola de Educação Física de Minas Gerais. Documento "Necessidades de Criação da Escola de Educação Física e Desportos de Minas Gerais", a Apresentado ao Exmo. Sr. Dr. MILTON SOARES CAMPOS, D.D. Governador do Estado de Minas Gerais - 10 de julho de 1947.

- Acervo do CEMEF/UFMG. Coleção Iconográfica.

\section{Em Montevidéu}

- Colección Fotográfica de la Comisión Nacional de Educación Física (1915 - 1960), pertencente ao Acervo Secretaría Nacional del Deporte (SND) e em processo de organização no Centro de Fotografía de Montevideo (Cdf).

\section{REFERÊNCIAS}

DESVALLÉES, André; MAIRESSE, François. Conceitos-chave de museologia. São Paulo: ICOM: Armand Colin, 2013. 98 p.

DOGLIOTTI, Paola. Educación del cuerpo y discursividades en torno a la formación en educación física en Uruguay (1874 - 1948). Montevideo: Universidad de la República. CSIC. Biblioteca Plural, 2015. 259 p.

GRUZINSKI, Serge. Que hora são...Lá, do outro lado? América e Islã no limiar da época moderna. Belo Horizonte: Autêntica, 2012.

LINHALES, Meily Assbú; NASCIMENTO, Adalson (Orgs.). Organizando arquivos, produzindo nexos: a experiência de um Centro de Memória. Belo Horizonte: Fino Traço, 2013.

et al. Arquivos pessoais de professores de educação física: organização arquivística e pesquisa histórica. Rev Bras Ciênc Esporte. 39(3), p. 276-283, 2017. 
et al. Organização de acervos arquivísticos: a experiência do Centro de Estudos sobre a Memória da Educação Física, do Esporte e do Lazer da UFMG. Anais do VI Congresso Brasileiro de História da Educação. Vitória: Sociedade Brasileira de História da Educação, 2011.

A escola e o esporte: uma história de práticas culturais. São Paulo: Cortez, 2009.

MORENO, Andrea; SEGANTINI, Verona Campos. Sobre fotografias: da coleção à fonte. In: LINHALES, Meily Assbú; NASCIMENTO, Adalson (Orgs.). Organizando arquivos, produzindo nexos: a experiência de um Centro de Memória. Belo Horizonte: Fino Traço, 2013, p. 103-115.

SCARLATO, Inés. Corpo e tempo livre. As plazas vecinales de cultura física em Montevidéu (1911-1915). Florianópolis, SC, Biblioteca Universitária da UFSC, 2015. 152 p.

SEGANTINI, Verona Campos; JULIÃO, Leticia. A UFMG e o patrimônio da ciência e cultura: da obsolescência à musealização. In: GRANATO, Marcus; RIBEIRO, Emanuela Sousa; ARAÚJO Bruno Melo de (Org.). Cadernos do Patrimônio da Ciência e Tecnologia: instituições, trajetórias e valores. Disponível em <http://site.mast.br/hotsite_cadernos_do_patrimonio_da_ciencia_e_tecnologia/index.html >. Rio de Janeiro: MAST, 2017. (v. 1)

SILVA, Giovanna Camila da. A partir da Inspetoria de Educação Física de Minas Gerais (1927-1937): Movimentos para a escolarização da Educação Física no Estado. 2009. 229 f. Dissertação (Mestrado em Educação) - Faculdade de Educação da UFMG. 